\title{
Policy Implications of Ageing Sexualities
}

\author{
Brian Heaphy*1 and Andrew K. T. Yip** \\ *School of Social Sciences, University of Manchester \\ E-mail: brian.heaphy@manchester.ac.uk \\ **School of Social Sciences, Nottingham Trent University \\ E-mail: a.yip@ntu.ac.uk
}

This article aims to open up debate on the policy implications of ageing sexualities. The article begins by discussing the heteronormative perspective that frames current discourse on older people's needs and citizenship. It then presents data from an empirical study to highlight the concerns that older lesbians and gay men have about housing, health and social service provision, work and job security, and relationship recognition. The article illustrates how the heterosexual assumption that informs policy making can limit the development of effective strategies for supporting older lesbians and gay men; and raises broader questions about policy making, social inclusion and citizenship.

\section{Introduction}

Recent years have witnessed a growing recognition among researchers, policy makers and social service providers of the changing and diverse living circumstances of the older population (e.g. Minichiello, Browne and Kending, 2000; Bernard and Phillips, 2000). There is also an increasing awareness of how socio-cultural factors impact on life circumstances and influence access to resources and support. These factors - most often discussed in terms of gender, social class, ethnicity and disability - are crucial to understanding the potential for social exclusion in later life. Thus, the challenge for policy making is to grapple with the changing and diverse needs of the ageing population, and the complex causes of marginalisation (Evandrou, 1998; Bernard and Phillips, 2000). Some argue that policy makers must therefore recognise the older population as not only consumers of services, but also 'citizens' (Simey, 1998: 254).

Current discourse on older people's needs and citizenship is framed by a heteronormative perspective, which marginalises lesbians and gay men. It is only recently that some advocates for older people have recognised the existence of older lesbians and gay men. For instance, Age Concern, in 2001, acknowledged that the 'invisibility' of older lesbians and gay men at all levels of relevant policy means that they face particular risks of exclusion (Smith and Calvert, 2001).

Old age raises the possibility for social exclusion irrespective of one's sexuality (Bernard and Phillips, 1998). However, being old and lesbian or gay compounds such possibility (Cahill, South and Spade, 2000). Later life is a time when issues of recognition, support and dependency can become particularly salient. Thus, policies in relation to such

\footnotetext{
${ }^{1}$ Corresponding author.
} 
issues have profound implications for quality of life (Bernard and Philips, 1998). As an 'unseen minority' (Brown, Sarosy, Cook and Quarto, 1997), the specific concerns of older lesbians and gay men, and the implications of their sexual identities for compromised citizenship in later life, are issues that have hitherto been largely neglected by policy makers, advocates for older people and lesbian and gay communities (Cahill, South and Spade, 2000).

Nevertheless, increasing social and legal recognition of non-hetersoexual lifestyles means that older lesbians and gay men are likely to become more vocal about their rights as citizens. Therefore, policy makers and service providers are encountering the first wave of older lesbians and gay men who want to live their lives openly as sexual citizens, but whose lifestyles are at odds with policy and service provision that are underpinned by a 'heterosexual assumption' (Donovan, Heaphy and Weeks, 1999; Cahill, South and Spade, 2000).

Against this backdrop, we explore, in this paper, a number of policy-relevant issues through the perceptions and experiences of older lesbians and gay men. In attempting to open up the debate on the policy implications of ageing sexualities, we focus on areas that were of particular concern to participants in an empirical study. These areas are: living conditions and future housing, health and social services, work and job security and relationship recognition.

\section{Brief description of the study and the sample}

The data presented in this paper are drawn from a research project entitled 'Social and Policy implications of Non-heterosexual Ageing', undertaken in 2001 and 2002. ${ }^{1}$ The fieldwork included eight single-sex focus groups, a postal questionnaire survey of 266 lesbians and gay men and semi-structured interviews with a sub-sample of 20 (10 women and 10 men).

The participants, from across Great Britain, were recruited through user groups, personal networks, snowballing, publicity in printed media and the internet. The study recruited participants aged 50 and above to gather prospective and retrospective data. The survey participants, whose ages range from the 50s to the 80s, consisted of 102 women (38 per cent) and 164 men (62 per cent). ${ }^{2}$ Overall, 64 per cent of the women, and 43 per cent of the men were in full-time or part-time employment. Further, 51 women (50 per cent) and 110 men (67 per cent) classified themselves as financially secure (for more details, see Heaphy, Yip and Thompson, 2003)

\section{Living conditions, housing and care}

Since the late 1980s, social policies regarding later life have been concerned with facilitating independent living (Peace and Johnson, 1998). While these are framed by the discourse of promoting autonomy and citizenship, they also seek to reduce the costs on the state. This focus on independence is consistent with the participants' aspirations. Approximately 91 per cent of the participants either lived alone (41 per cent of women and 65 per cent of men) or with a partner; and the likelihood of solo living gradually increased with age. The participants generally reported a high level of satisfaction with the current living arrangement, and expressed considerable concern about being unable to continue with this in the future. 
However, less than one-third of the sample reported that they had made any specific plans for future living arrangements. Only 20 women and 18 men had planned for care in the case of serious illness, and only nine women and 14 men had made plans for care in old age. The tendency was to delay making contingency plans for the loss of independence, often due to the anxiety that the idea generated.

Most participants acknowledged that the loss of independence would imply a reliance on health and social care professionals, especially if they could not rely on a partner. This is where their sexuality becomes a prominent issue, as the following table on the desirability of supported living arrangements demonstrates.

Table 1 Levels of desirability of various living arrangement with care support

\begin{tabular}{|c|c|c|c|}
\hline \multirow[b]{2}{*}{ Type of living arrangement } & \multicolumn{3}{|c|}{$\begin{array}{l}\text { Number and percentage of participants } \\
\text { who considered the arrangement 'desirable' } \\
\text { or 'highly desirable' }\end{array}$} \\
\hline & $\begin{array}{l}\text { Entire sample } \\
(N=266)\end{array}$ & $\begin{array}{l}\text { Women } \\
(N=102)\end{array}$ & $\begin{array}{l}\text { Men } \\
(N=164)\end{array}$ \\
\hline Sheltered housing & $121(46 \%)$ & $47(46 \%)$ & $74(45 \%)$ \\
\hline Care/residential homes & $20(8 \%)$ & $8(8 \%)$ & $12(7 \%)$ \\
\hline $\begin{array}{l}\text { Sheltered housing run by lesbians and gay } \\
\text { men }\end{array}$ & $162(61 \%)$ & $67(66 \%)$ & $95(58 \%)$ \\
\hline $\begin{array}{l}\text { Care/residential homes run by lesbians and } \\
\text { gay men }\end{array}$ & $120(45 \%)$ & $50(49 \%)$ & $70(43 \%)$ \\
\hline
\end{tabular}

Table 1 clearly demonstrates that, if living at home was no longer a possibility, most of the participants would prefer to live in sheltered housing which offers more independence compared to care/residential homes. However, the level of desirability of both kinds of living arrangement increases substantially if they are run by lesbians or gay men. Qualitative data offer a consistent analysis, illustrated by the following quotation:

This is something I've thought about ... [and I've] met a lot of people in these circumstances ... [who said] to go into a residential home as a gay person ... your life would be hell. John, aged 80)

The participants' concern about their quality of life in special housing focuses on the implications of such living arrangements for their sexuality, and vice versa. They were concerned about being discriminated against, stigmatised or harassed by fellow residents and care professionals. Here, the issues of fear and trust are significant. Despite increasing social tolerance towards homosexuality, participants shared the view that older people's sexuality (especially homosexuality) is still generally seen as problematic. Hence, to be openly lesbian or gay in a special housing setting was deemed by many to be unimaginable.

Most of the participants acknowledged that, judging from current development in social services for lesbian and gay communities, it is unlikely that they could choose to live in special housing specifically for lesbians and gay men. A more achievable target is to promote better understanding of their concerns among care professionals. Unsurprisingly, 
a large majority (76 per cent) thought that it is important for care to be delivered by professionals who are tolerant of, and knowledgeable about, lesbian and gay lifestyles. While few were confident that this need would be met, it does highlight the importance of awareness to be incorporated in the training of care professionals, as well as the general social environment of such living arrangements. The development, enactment and practice of anti-discrimination policies are of paramount importance in these contexts. In terms of facilitating trust, however, other steps could be taken to make explicit that such policies are in place and adhered to. For example, the providers and regulators of specialist housing could adopt a kite-marking scheme, indicating that staff are knowledgeable about the concerns of lesbian and gay clients.

\section{Health needs and social services}

Trust and recognition are also salient issues in terms of how older lesbians and gay men view health professionals. Many participants expressed concerns about the complications that their sexuality could pose in their interactions with health professionals. Table 2, outlining participants' attitudes towards health professionals, illustrates this:

Table 2 Participants' attitudes towards health professionals

\begin{tabular}{llll}
\hline \hline & \multicolumn{2}{l}{$\begin{array}{l}\text { Number and percentage of participants who } \\
\text { 'agreed' or 'strongly agreed' with statement }\end{array}$} \\
\cline { 2 - 4 } & $\begin{array}{l}\text { Entire sample } \\
(N=266)\end{array}$ & $\begin{array}{l}\text { Women } \\
(N=102)\end{array}$ & $\begin{array}{l}\text { Men } \\
(N=164)\end{array}$ \\
\hline Statement & $142(53 \%)$ & $53(52 \%)$ & $89(53 \%)$ \\
\hline $\begin{array}{l}\text { I am out (open) about my sexuality to health } \\
\text { professionals }\end{array}$ & $92(35 \%)$ & $25(25 \%)$ & $67(41 \%)$ \\
$\begin{array}{l}\text { Health professionals are generally positive } \\
\text { towards lesbian, gay, and bisexual clients }\end{array}$ & $43(16 \%)$ & $8(8 \%)$ & $35(21 \%)$ \\
$\begin{array}{l}\text { Health professionals are generally } \\
\text { knowledgeable about lesbian, gay, and } \\
\text { bisexual lifestyles }\end{array}$ & & & \\
\hline \hline
\end{tabular}

Table 2 demonstrates the extent of participants' lack of confidence - and therefore trust - in health professionals. It also suggests that this lack of trust and confidence may be more prevalent amongst women than men. We can only speculate as to why this might be the case. The qualitative data, however, suggest that female participants may perceive themselves to be 'doubly' disadvantaged (as women and lesbians) in their dealings with male-dominated professions such as the medical profession. Further, as a consequence of the association made between HIV infection and gay male sexuality since the $1980 \mathrm{~s}$, the issue of health professionals' attitudes toward, and knowledge about, gay male lifestyles has been politicised. It is therefore likely that some health service providers have become more attuned to the needs of gay men, especially in urban areas with large gay male populations. In terms of actual experience, among participants who were open about their sexuality in their interactions with health professionals, 45 per cent of the women and 22 per cent of the men reported that they had encountered prejudice and discrimination. 
The participants' concern about health professionals' negative assumption of, or general lack of knowledge about, their lifestyles is also evident in the qualitative data:

My doctor sees everything, everything, related [to being gay] ... depression, which I suffer from as well, was related to it. (Mark, aged 59)

I mean communication anyway is a problem for anyone who's a patient ... but if you're a lesbian or if you're gay, the whole process is much more traumatic, because of the expectations. (Gloria, aged 54)

There is broad agreement amongst participants that health professionals and health service providers operate according to a heterosexual assumption. Many participants went along with this assumption due to fears about prejudice and breaches in confidentiality. Gay men also pointed to the consequences that disclosure might have for assumptions about HIV infection (e.g. being denied health and life insurance). Not surprisingly, 62 per cent of women and 45 per cent of men indicated that they would welcome health services and/or sources of information specifically for lesbian and gay communities.

Among participants who had regular contact with social services of various kinds, only approximately one-third considered social services agencies welcoming to lesbian and gay clients; and about the same were willing to be open about their sexuality with social services professionals. Many participants perceived social service providers as unwilling to explicitly acknowledge their vulnerability to prejudice, harassment and breaches in confidentiality. They viewed this as a form of invalidation that generated a lack of trust.

As with the previous section, the data presented here highlight the importance of promoting, among health and social service professionals, better awareness of the concerns that older lesbians and gay men have. While it is difficult to evaluate the impact of these concerns on the support that older lesbians and gay men seek and receive, demonstrating sensitivity to them is undoubtedly an important first step in building trust, thus enhancing access to the available services.

\section{Work and job security}

Participation and position in the labour market throughout the life-course is a primary determinant of financial security in later life, which has consequent implications for life choices. A significant proportion of the sample (34 per cent of women and 43 per cent of men) reported that they felt vulnerable to discrimination at work. While such perceptions need not lead to actual experience, 30 per cent of women and 20 per cent of men indicated that their sexuality had had negative consequences in their working lives. These participants had encountered discrimination and hostility at work, damaging their career progression. Some had even lost their jobs as a result. The quotes below from questionnaires demonstrate the significant effect that one's sexuality could have on an individual's working life:

My ... career in [company's name] ended when they found out I was a lesbian. (Sandra, aged 58 years)

My options were limited due to conviction (at 17) for gross indecency - $1950 \mathrm{~s}$ witch hunt [against homosexuals]. (Peter, aged 65 years) 
The research took place before the enactment of the 2003 Employment Equality (Sexual Orientation) Regulations, which made discrimination against lesbian and gay people in the workplace unlawful. Nevertheless, employers' commitment to the enforcement of the legislation remains to be seen. Also, the data suggest that discrimination and harassment in the workplace often operates in subtle and covert ways that are difficult to challenge legally. This compounds the relationship between legal reform, broader cultural changes and attitudes and experience 'on the ground'. While participants viewed legal reform as essential to enhancing a sense of citizenship, many shared the view that legislation alone would not undermine mundane manifestations of homophobia (e.g. derogatory remarks and jokes) that were perceived to be acceptable in many workplace cultures, as it was in the culture more generally.

Finally, it is worth noting the consequences that workplace discrimination had for a significant number of our participants. These could include diminished financial resources in later life, and increased reliance on state support and public services that, as we have seen in the previous sections, are often perceived to be inadequate in catering for older lesbians and gay men.

\section{Relationship recognition}

For the participants, the most contentious - and policy relevant - issue in terms of relationships is that of couple relationships. The research was carried out before the Civil Partnership Act was enacted which, from December 2005, legalised same-sex partnerships in the United Kingdom. The couple - as registered civil partners - would acquire rights and responsibilities broadly similar to heterosexual married couples. These rights include survivor pension, inheritance tax, next of kin rights, tenancy succession rights, bereavement benefits and so forth (see Stonewall, 2005).

Some may argue that this development renders irrelevant major concerns about the inequality of same-sex relationships compared with heterosexual marriage. We would argue that it is still crucial to consider our participants' concerns, for a number of reasons. First, positive legislative development may not be reflected in other social contexts, where same-sex couples could still be subjected to discrimination. Indeed, at least two local councils (i.e. Bromley in London and Lisburn in Northern Ireland) had initially refused to allow ceremonies celebrating same-sex civil partnerships in their Council buildings. Second, registration of same-sex relationship requires the couple to go public, at least to a certain extent, which is likely to be problematic to those in 'closeted' relationships, and those who perceive themselves to be vulnerable to prejudice and harassment. Finally, while some view the Act as a great leap forward in terms of lesbian and gay equality, others argue that it is a 'marriage-lite' arrangement that is unequal as well as socially and politically conservative (Holt, 2004).

The aforementioned first point is demonstrated clearly in the following account, by a participant who was denied the right to be buried with his partner:

I went to see the vicar when [partner] died and ... [the vicar said] there was just a single grave available. After my partner was buried, I talked to the grave worker. He said, 'Well all you have to do is when you say... want a double grave digging. ' ... So I've been denied the opportunity of being buried with [my partner], simply because I'm gay. (Bob, aged 72) 
Indeed, a substantial 84 per cent of the sample argued that their relationships are not validated in the broader society. Almost all (99 per cent) acknowledged that the law does not place equal value on same-sex relationships as heterosexual ones. In the area of pensions, Smith and Calvert (2001) reported that while new 'stakeholder pension schemes' allow individuals to nominate a partner of their choice (and Trustees have no choice but to award survivor benefits to the nominated person), this is only a recent development. Currently, few public sector pension schemes make any provision for same-sex partners. This highlights the need to ensure that pension rights enshrined in the Civil Partnership Act are adopted in all pension schemes.

Before the Civil Partnership Act, the estate of a deceased member of a same-sex relationship would pass automatically to his or her family (as 'next of kin') and not the same-sex partner. Unsurprisingly, the participants acknowledged the importance of wills in order to preclude this. Some 88 per cent of the sample considered drawing up a will particularly important for lesbians and gay men, and 82 per cent had already taken this step. Indeed, wills are often seen as a response to risk, as the following participant argued:

My ex-partner was paranoid about being safe...we made wills... everything was in joint names... [we] were concerned that her family would... be able to hone in and do things, so at one stage I got enduring power of attorney... without that you're fairly stuffed, you can be denied access to hospital, or wherever. (Rosemary, aged 51)

It is undeniable that the Civil Partnership Act is a milestone in the legal recognition of same-sex partnerships. However, the advancement in legal reform often takes a long time to filter down to more specialised areas of policy and practice, more so in changing social attitudes (Yip, 2006). For instance, having the legal right to act as next of kin in the event of a partner's death does not guarantee one's interactions with officialdom (e.g. hospital) would be plain sailing. We would argue that policy makers and practitioners in various areas need specific guidance in building this Act appropriately into their practices, and be trained to operate them with sensitivity.

It should also be acknowledged that, premised on the primacy of the coupled relationship, the Act fails to account for the other kinds of relationships that are significant to lesbians and gay men. For example, some research suggests a high prevalence of nonmonogamy in lesbian and gay cultures, and that individuals can often have more than one significant partner-type relationship - as was the case for some of our participants (Heaphy, Donovan and Weeks, 2004; Yip, 1997). Further, such polices fail to acknowledge the integral role of ex-partners and friends as crucial providers of care and support for lesbians and gay men. Our research suggests that such relationships are particularly important sources of emotional, material and caring support for older lesbians and gay men, many of whom consider ex-partners and friends as 'families of choice' (see also Weston, 1991; Weeks, Heaphy and Donovan, 2001). It is therefore necessary to more fully and systematically interrogate and challenge how the heterosexual assumption currently informs policy making, so that effective strategies for supporting lesbian and gay later lives can be developed.

\section{Conclusion}

We have argued that the lack of explicit recognition of lesbian and gay lives in policy making, service provision and law can lead to a profound sense of invalidation. Ageing 
can exacerbate this sense of second-class citizenship, as is demonstrated in the following quote:

When you're older it becomes perfectly obvious to you that you are, you can be discriminated against ... You haven't got the same rights as other people in terms of your legal and financial rights ... And that's partly part of the invisibility thing ... We don't exist therefore we don't need any legislation. (Gloria, aged 54)

The issues raised in this paper highlight how the heteronormative values underpinning policy and law lead to a sense of social exclusion among older lesbians and gay men. This is rarely accounted for in contemporary policy or political discourse on 'social exclusion' (cf. Morris, 2001). In this connection, Levitas (1998: 7) develops a typology of discourse on social exclusion, identifying three 'ideal types'. These are:

a redistributionist discourse developed in British critical social policy ... whose prime concern is with poverty; a moral underclass discourse ... which centres on the moral and behavioural delinquency of the excluded themselves; and a social integrationist discourse whose central focus is on paid work... They differ in how they characterize the boundary, and thus what defines people as insiders and outsiders, and how inclusion can be brought about.

We would argue that a broader conception of social exclusion is necessary to address the dynamics of exclusion in the case of older lesbians and gay men who, despite recent legal reform, still considered themselves to have diminished recognition and 'rights' in policy and law. As with the contemporary discourses of social exclusion, traditional narratives of citizenship cannot fully comprehend the kinds of 'rights' that the participants are arguing for. A number of sexuality theorists have, however, begun to develop the concept of citizenship in a way that is more applicable to our participants' experiences (Plummer, 1995; Richardson, 1998; Weeks, 1998). In short, they emphasise that participation in citizenship is, in many ways, premised on being heterosexual (Donovan, Heaphy and Weeks, 1999). Recognition and validation as sexual citizens is important for the participants, as is the degree to which their life choices, identities and ways of living can be invalidated - especially in later life. The participants' experiences therefore highlight the complexity of social inclusion and citizenship in contemporary social contexts - and raises questions about the ways in which policy can act to limit or facilitate these.

\section{Notes}

1 The project was funded by the Economic and Social Research Council (Award ref. no: R00223465). Brian Heaphy and Andrew Yip are the principal investigators. They wish to express their gratitude to the ESRC, all participants, user groups, and Debbie Thompson as the research assistant.

2 'The sample' and all percentages in this paper refer to the 266 participants who completed the postal questionnaires. All quantitative data are drawn from this dataset, and percentages are rounded off to the nearest whole number. All quotations are from the focus group data (unless indicated otherwise), some of which were generated collaboratively with Liz Bassett of the University of Brighton.

\section{References}

Bernard, M. and Phillips, J. (1998), The Social Policy of Old Age: Moving into the 21st Century, London: The Centre for Policy on Ageing. 
Bernard, M. and Phillips, J. (2000), 'The challenge of ageing in tomorrow's Britain', Ageing and Society, 20, 1, 33-54.

Brown, L., Sarosy, S., Cook, T., and Quarto, J. G. (1997), Gay Men and Ageing, New York: Garland Publishing.

Cahill, S., South, K., and Spade, J. (2000), Outing Age: Public Policy Issues Affecting Gay, Lesbian, Bisexual and Transgender Elders, Washington, DC: The Policy Institute of The National Gay and Lesbian Task Force Foundation.

Donovan, C., Heaphy, B., and Weeks, J. (1999), 'Citizenship and same-sex relationships', Journal of Social Policy, 28, 4, 689-709.

Evandrou, M. (1998), 'Great expectations: social policy and the new millennium elders', in M. Bernard and J. Phillips (eds), The Social Policy of Old Age: Moving into the 21st Century, London: The Centre for Policy on Ageing, pp. 267-288.

Heaphy, B., Donovan, C., and Weeks, J. (2004), 'A different affair: openness and nonmonogamy in same sex relationships', in J. Duncombe, K. Harrison, G. Allen, and D. Marsden (eds), The State of Affairs, Mahwah, NJ: Erlbaum, pp. 167-186.

Heaphy, B., Yip, A. K. T., and Thompson, D. (2003), Lesbian, Gay, and Bisexual Lives over 50, Nottingham: York House Publishing.

Heaphy, B., Yip, A. K. T., and Thompson, D. (2004), 'Ageing in a non-heterosexual context', Ageing and Society, 24, 881-902.

Holt, M. (2004), "'Marriage-like" or married?: lesbian and gay marriage, partnership and migration', Feminism and Psychology, 14, 1, 30-35.

Levitas, R. (1998), The Inclusive Society?: Social Exclusion and New Labour, Basingstoke: Palgrave MacMillan.

Minichiello, V., Browne, J., and Kending, H. (2000), 'Perceptions and consequences of ageism: view of older people', Ageing and Society, 20, 253-278.

Morris, J. (2001), 'Social exclusion and young disabled people with high levels of support needs', Critical Social Policy, 21, 2, 161-183.

Peace, S. and Johnson, J. (1998), 'Living arrangements of older people', in M. Bernard and J. Phillips (eds), The Social Policy of Old Age: Moving into the 21st Century, London: The Centre for Policy on Ageing, pp. 56-75.

Plummer, K. (1995), Telling Sexual Stories: Power, Change and Social Worlds, London: Routledge.

Richardson, D. (1998), 'Sexuality and citizenship', Sociology, 32, 1, 83-100.

Scott, A. and Wenger, G. (1995), 'Gender and social support networks in later life', in S. Arber and J. Ginn (eds), Connecting Gender and Ageing: A Sociological Approach, Buckingham: Open University Press, pp. 158-172.

Simey, M. (1998), 'The politics of old age', in M. Bernard and J. Phillips (eds), The Social Policy of Old Age: Moving into the 21st Century, London: The Centre for Policy on Ageing, pp. 253-266.

Smith, A. and Calvert, J. (2001), Opening Doors: Working with Older Lesbians and Gay Men, London: Age Concern.

Stonewall (2005), 'Partnership', http://www.stonewall.org.uk/stonewall/information_bank/partnership/ Accessed 22 June 2005.

Weeks, J. (1998), 'The sexual citizen', Theory, Culture and Society, 15, 3-4, 35-52.

Weeks, J., Heaphy, B., and Donovan, C. (2001), Same Sex Intimacies: Families of Choice and Other Life Experiments, London: Routledge.

Weston, K. (1991), Families We Choose: Lesbians, Gays and Kinship, New York: Columbia University Press.

Yip, A. K. T. (1997), 'Gay male Christian couples and sexual exclusivity', Sociology, 31, 289-306.

Yip, A. K. T. (2006), 'Sexual orientation discrimination in religious communities', in J. Frank and L. Badgett (eds), Sexual Orientation Discrimination, London: Routledge. 